\title{
Neonatal odor-shock conditioning alters the neural network involved in odor fear learning at adulthood
}

\author{
Yannick Sevelinges, ${ }^{1,3}$ Regina M. Sullivan, ${ }^{2}$ Belkacem Messaoudi, ${ }^{1}$ \\ and Anne-Marie Mouly ${ }^{1}$ \\ ${ }^{1}$ Neurosciences Sensorielles, Comportement, Cognition, CNRS-Université de Lyon, Lyon IFR 19, France;
${ }^{2}$ Department of Zoology, University of Oklahoma, Norman, Oklahoma 73019, USA
}

Adult learning and memory functions are strongly dependent on neonatal experiences. We recently showed that neonatal odor-shock learning attenuates later life odor fear conditioning and amygdala activity. In the present work we investigated whether changes observed in adults can also be observed in other structures normally involved, namely olfactory cortical areas. For this, pups were trained daily from postnatal (PN) 8 to 12 in an odor-shock paradigm, and retrained at adulthood in the same task. ${ }^{14} \mathrm{C}$ 2-DG autoradiographic brain mapping was used to measure training-related activation in amygdala cortical nucleus $(\mathrm{CoA})$, anterior $(\mathrm{aPCx})$, and posterior $(\mathrm{pPCx})$ piriform cortex. In addition, field potentials induced in the three sites in response to paired-pulse stimulation of the olfactory bulb were recorded in order to assess short-term inhibition and facilitation in these structures. Attenuated adult fear learning was accompanied by a deficit in 2-DG activation in CoA and PPCx. Moreover, electrophysiological recordings revealed that, in these sites, the level of inhibition was lower than in control animals. These data indicate that early life odor-shock learning produces changes throughout structures of the adult learning circuit that are independent, at least in part, from those involved in infant learning. Moreover, these enduring effects were influenced by the contingency of the infant experience since paired odor-shock produced greater disruption of adult learning and its supporting neural pathway than unpaired presentations. These results suggest that some enduring effects of early life experience are potentiated by contingency and extend beyond brain areas involved in infant learning.

Neonatal experiences have profound effects on adult learning and memory, as well as the supporting neural structures. Most studies in this domain are related to the effect of early stress, mainly maternal separation/deprivation (Anisman et al. 1998; Fleming et al. 1999; Levine 2001, 2005; Pryce and Feldon 2003; Teicher et al. 2006), or alterations of level of maternal care (Zhang et al. 2006). Recently, we showed that some aspects of the enduring impact of early life adverse experience are dependent upon the learned contingencies of the experience. Specifically, infant paired odor-shock produces significantly greater attenuation of adult fear learning as assessed through freezing response, compared to infant unpaired presentations (Sevelinges et al. 2007). We also showed that this attenuated learning was associated with a decrease in amygdala 2-DG uptake whereas an increase was observed in the olfactory bulb (OB). This led us to suggest that, under the influence of learning, early experiences may be able to shape the neural circuits that would normally be used at adulthood. This question was further addressed in the present work by investigating more specifically the effects of neonatal odor-shock learning on other potential targets of the adult network, namely olfactory cortical areas including piriform cortex and cortical nucleus of the amygdala (CoA).

Recent studies on the ontogeny of fear learning (i.e., odor$0.5 \mathrm{~mA}$ shock conditioning) have highlighted the emergence of this amygdala-dependent learning at postnatal (PN) day 10. Before this age, odor-shock associations paradoxically induce an odor preference (Stehouwer and Campbell 1978; Haroutunian and Campbell 1979; Camp and Rudy 1988; Sullivan et al. 2000) despite pups feeling pain from shock (Collier and Bolles 1980;

\footnotetext{
${ }^{3}$ Corresponding author.
}

E-mail yannicksevelinges@yahoo.fr; fax 33-2-47-42-77-43.

Article is online at http://www.learnmem.org/cgi/doi/10.1101//m.998508.
Barr 1995; Fitzgerald 2005). The neural network sustaining this paradoxical preference involves $\mathrm{OB}$ and anterior piriform cortex (aPCx) whereas the amygdala does not appear to participate in the circuit (Sullivan and Wilson 1995; Roth and Sullivan 2005; Moriceau et al. 2006). In contrast around PN 10, pups readily learn aversion to odors paired with shock and the network involved in this learned aversion includes posterior piriform cortex (pPCx) and amygdala (Sullivan and Wilson 1995; Sullivan et al. 2000; Roth and Sullivan 2005; Moriceau et al. 2006).

In adult rats, consistent with auditory fear conditioning (Davis 1997; LeDoux 2000; Fanselow and Gale 2003), odor fear learning was shown to involve the basolateral complex (BLCA) of the amygdala (Cousens and Otto 1998; Funk and Amir 2000; Schettino and Otto 2001; Rosenkranz and Grace 2002; Kilpatrick and Cahill 2003; Sevelinges et al. 2004; Walker et al. 2005). In addition, we recently showed that the CoA, which constitutes the primary amygdaloid target of olfactory information (Price 1973; McDonald 1998; Swanson and Petrovich 1998), as well as the pPCx both showed synaptic changes following olfactory fear conditioning (Sevelinges et al. 2004), suggesting their involvement in this learning. Therefore, the neural network sustaining odor-shock learning evolves from infancy to adulthood from a circuit including $\mathrm{OB}$ and $\mathrm{aPCx}$ supporting odor preference, toward a circuit including pPCx, BLcA, and CoA supporting odor aversion.

In our previous study (Sevelinges et al. 2007) we showed that early odor-shock learning induced a deficit in adult odor fear learning associated with opposite changes in the amygdala (decrease) and $\mathrm{OB}$ (increase) as revealed by 2-DG mapping. The main entrance for the olfactory information from the $\mathrm{OB}$ onto the amygdala is through the CoA, either directly or by way of the piriform cortex. Therefore, the aim of the present work was to assess whether early learning induced changes in these two in- 
termediate areas. For this, pups were trained daily from PN8 to PN12 in an odor-shock conditioning paradigm, and retrained at adulthood in the same task. In adult rats, two complementary neurobiological techniques were used to assess the CoA, pPCx, and aPCx functioning. First, autoradiographic ${ }^{14} \mathrm{C}$ 2-DG brain mapping was used to visualize the activity of these structures during learning acquisition. Second, because the 2-DG technique does not distinguish between excitatory and inhibitory neural activity, evoked field potentials (EFPs) were induced in these sites after learning, using paired-pulse electrical stimulation of the OB, in order to assess short-term inhibition and facilitation phenomenon at these different levels. In a subset of animals, we also recorded EFPs in the $\mathrm{OB}$, which provides the main input to these cortical areas, using electrical stimulation of the lateral olfactory tract (LOT). This last experiment was made in order to further investigate whether the changes observed in the olfactory cortical areas were local or could be explained by modifications in the OB.

\section{Results}

\section{Behavioral data}

\section{Infant odorant CS test}

Pups' learning was verified in 15 pups not trained at adulthood. PN13 pups trained in the Paired condition from PN8 to PN12 demonstrated a shock-induced odor preference, whereas control pups (Unpaired or Odor Only) did not exhibit such preference (Fig. 1A). ANOVA confirmed a main effect of condition $\left(F_{(2,12)}=10.429, P<0.01\right)$. Post-hoc Fisher tests showed that the Paired group was significantly different of the two control groups $(P<0.01)$ whereas Unpaired and Odor-Only groups were not different $(P=0.65)$.

\section{Adult learning}

At adulthood, animals of the different groups were trained in a paired odor-shock paradigm, using the same odor as in infancy. Freezing behavior measured $24 \mathrm{~h}$ later in response to odor cue alone in the different experimental groups (Infant Paired/Adult Paired, Infant Unpaired/Adult Paired, Infant Naive/Adult Paired) is illustrated in Figure 1B. ANOVA revealed a main effect for condition $\left(F_{(2,17)}=9.39, P<0.005\right)$, odor $\left(F_{(1,17)}=155.65\right.$, $P<0.001)$, and their interaction $\left(F_{(2,17)}=9.44, P<0.005\right)$. Further comparisons showed that, although animals in the three groups presented a significant increase in freezing behavior when the odor was introduced $(P<0.05)$, animals in Infant Paired/ Adult Paired group presented a significantly lower level of freez-

ing than animals in the others two groups (post-hoc Fisher test, $P<0.005)$. Infant Unpaired/Adult Paired and Infant Naive/Adult Paired animals displayed similar levels of freezing. These data replicate those obtained previously (Sevelinges et al. 2007).

\section{2-DG autoradiography data}

Autoradiographs, which were derived from animals during odorshock conditioning in adulthood, focused on the piriform cortex and CoA during acquisition. Twenty animals were used for this experiment and did not overlap with animals used for electrophysiology. The data are presented in Figure 2.

\section{Piriform cortex}

During conditioning, aPCx activity did not significantly differ between groups $\left(F_{(3,16)}=1.149, P=0.27\right)$. In contrast, in the pPCx ANOVA revealed a main effect of group condition $\left(F_{(3,16)}=4.736\right.$, $P<0.05)$. Post-hoc Fisher tests revealed that the Infant Naive/Adult Paired and Infant Unpaired/Adult Paired animals exhibited higher levels of 2-DG uptake than animals of each of the Infant Paired/Adult Paired and Infant Odor/Adult Odor animals at the $P<0.05$ level. Infant Paired/Adult Paired animals did not differ significantly from Infant Odor/Adult Odor animals.

\section{Cortical amygdala nucleus}

ANOVA revealed a main effect of group condition for the CoA $\left(F_{(3,15)}=6.610, P<0.005\right)$. Post-hoc Fisher tests revealed that the Infant Naive/Adult Paired and Infant Unpaired/Adult Paired animals exhibited higher levels of 2-DG uptake than animals of each of the Infant Paired/Adult Paired and Infant Odor/Adult Odor animals at the $P<0.05$ level. Infant Paired/Adult Paired animals did not differ significantly from Infant Odor/Adult Odor animals.

In summary, whereas normal fear learning was associated with increased 2-DG uptake in pPCx and CoA, the attenuated freezing seen in Infant Paired/Adult Paired animals was associated with reduced 2-DG uptake in pPCx and in the CoA during conditioning.

\section{Electrophysiological data}

To better characterize the consequences of neonatal experience in the adult brain, field potentials were induced in $\mathrm{aPCx}, \mathrm{pPCx}$, and $\mathrm{CoA}$ in response to electrical stimulation of the $\mathrm{OB}$, and in the $\mathrm{OB}$ in response to electrical stimulation of the LOT. Paired-pulse stimulation with different interpulse interval (IPI) durations was used. EFPs were collected in the absence of odor presentation.

Figure 3 represents the paired-pulse ratios obtained in the different recording sites for the five IPI durations across the four experimental groups. A decrease in the size of the response to the second pulse suggests inhibition and is reflected in a score $<1$.

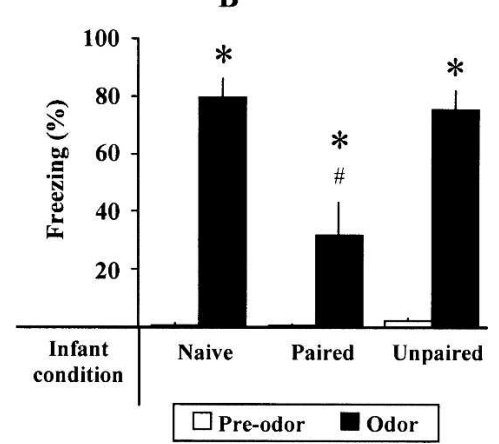

Figure 1. Behavioral performances in infant and adult animals during CS retention test carried out the day after odor-shock conditioning. $(A)$ Infant learning: mean number of choices toward CS odor at PN13. (B) Adult learning: mean percentage $( \pm$ SEM) of adult freezing behavior before and during CS odor presentation. $\left(^{*}\right)$ Significant intragroup difference with the pre-odor period $(P<0.05)$. (\#) Significant intergroup difference $(P<0.05)$.

\section{Piriform cortex}

In the aPCX, ANOVA revealed a main effect of group condition $\left(F_{(3,43)}=0.039\right)$ and IPI $\left(F_{(4,172)}<0.001\right)$ but not their interaction. One-way ANOVAs were then carried out for each IPI duration, followed when authorized by post-hoc comparisons. For IPI of 30 and $40 \mathrm{msec}$, despite a trend to intergroups difference, ANOVA did not reach the significance level $(P=0.052$ and 0.051 , respectively), thus precluding further post-hoc comparisons. For IPI of 80 and $120 \mathrm{msec}$, paired-pulse ratios were significantly higher in Infant Paired/Adult Paired ani- 


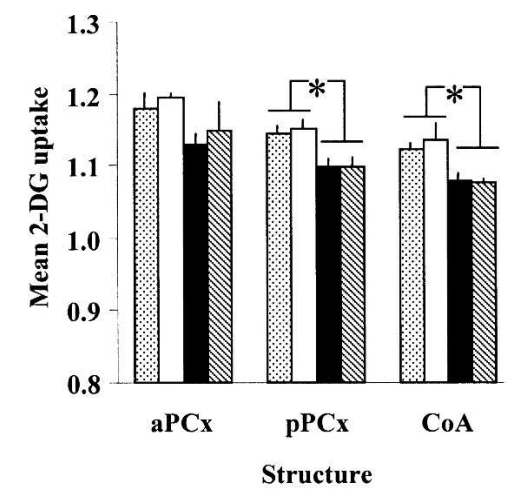

Infant Naive-Adult Paired $\quad \square$ Infant Unpaired-Adult Paired
Infant Paired-Adult Paired

Figure 2. Mean 2-DG uptake $( \pm S E M)$ relative to corpus callosum during adult fear conditioning in the different experimental groups, in three structures: anterior piriform cortex $(\mathrm{aPCx})$, posterior piriform cortex $(\mathrm{pPCx})$, and cortical nucleus of the amygdala (CoA). $\left(^{*}\right)$ Significant intergroup differences $(P<0.05)$.

mals than in the Infant Naive/Adult Paired and Infant Unpaired/ Adult Paired groups, whereas they did not differ significantly from Infant Naive/Adult Naive group.

In the pPCx, ANOVA revealed a main effect of condition $\left(F_{(3,43)}=7.49, P<0.001\right)$, IPI $\left(F_{(4,172)}=164.23, P<0.001\right)$, and their interaction $\left(F_{(12,172)}=2.34, P<0.01\right)$. Further post-hoc comparisons showed that, for all IPI, paired-pulse ratios were significantly higher in Infant Paired/ Adult Paired animals than in the other three groups $(P<0.05)$. Specifically, while paired-pulse inhibition was observed with the 20-msec interval (Infant Naive/Adult Naive, Infant Naive/Adult Paired, and Infant Unpaired/Adult Paired animals), it was absent in Infant Paired/Adult Paired animals. Moreover, for the 30-120-msec intervals, facilitation of the second pulse amplitude was observed in Infant Paired/Adult Paired animals compared to the other three groups.

\section{Cortical amygdala nucleus}

ANOVA revealed a main effect of group condition $\left(F_{(3,43)}=5.42, P<0.01\right)$, IPI $\left(F_{(4,172)}=115.08, P<0.001\right)$, and their interaction $\left(F_{(12,172)}=1.98, P<0.05\right)$. Further post-hoc comparisons showed that, for IPI of 20-80 msec, paired-pulse ratios were significantly higher in Infant Paired/Adult Paired animals than in the three other groups. For IPI of $120 \mathrm{msec}$, paired-pulse ratios were significantly higher in Infant Paired/Adult Paired animals than in Infant Naive/Adult Paired and Infant Unpaired/Adult Paired groups, whereas they did not differ significantly from the Infant Naive/Adult Naive group despite a strong tendency $(P=0.053)$. As for the pPCx, compared to the other groups, Infant Paired/Adult
Paired animals did not show paired-pulse inhibition for the 20msec interval and exhibited paired-pulse facilitation for the 30120 -msec intervals.

\section{Olfactory bulb}

ANOVA revealed no significant effect of group condition on the paired-pulse ratios in the $\mathrm{OB}\left(F_{(3,22)}=0.21, P=0.89\right)$. Pairedpulse ratios were similar in the four groups and were not significantly modified by early experience.

In summary, electrophysiological data highlighted longterm effects of early odor-shock learning, as observed in Infant Paired/Adult Paired group. In these animals, compared to the other groups, paired-pulse inhibition normally observed for 20msec interval in $\mathrm{pPCx}$ and $\mathrm{CoA}$ was abolished and paired-pulse facilitation was observed for 30-120-msec interval. Paired-pulse ratios in aPCx were only slightly affected in Infant Paired/Adult Paired group. Finally, no significant changes in paired-pulse ratios were detected in OB.

\section{Discussion}

The present study replicates our previous work suggesting that adult fear learning is altered by early life experience but also extends this work by expanding the assessment of the adult olfactory cortical areas of the learning circuit. Taken together, the present data show that Infant Paired/Adult Paired animals, which exhibited an attenuated adult odor fear, presented a deficit in
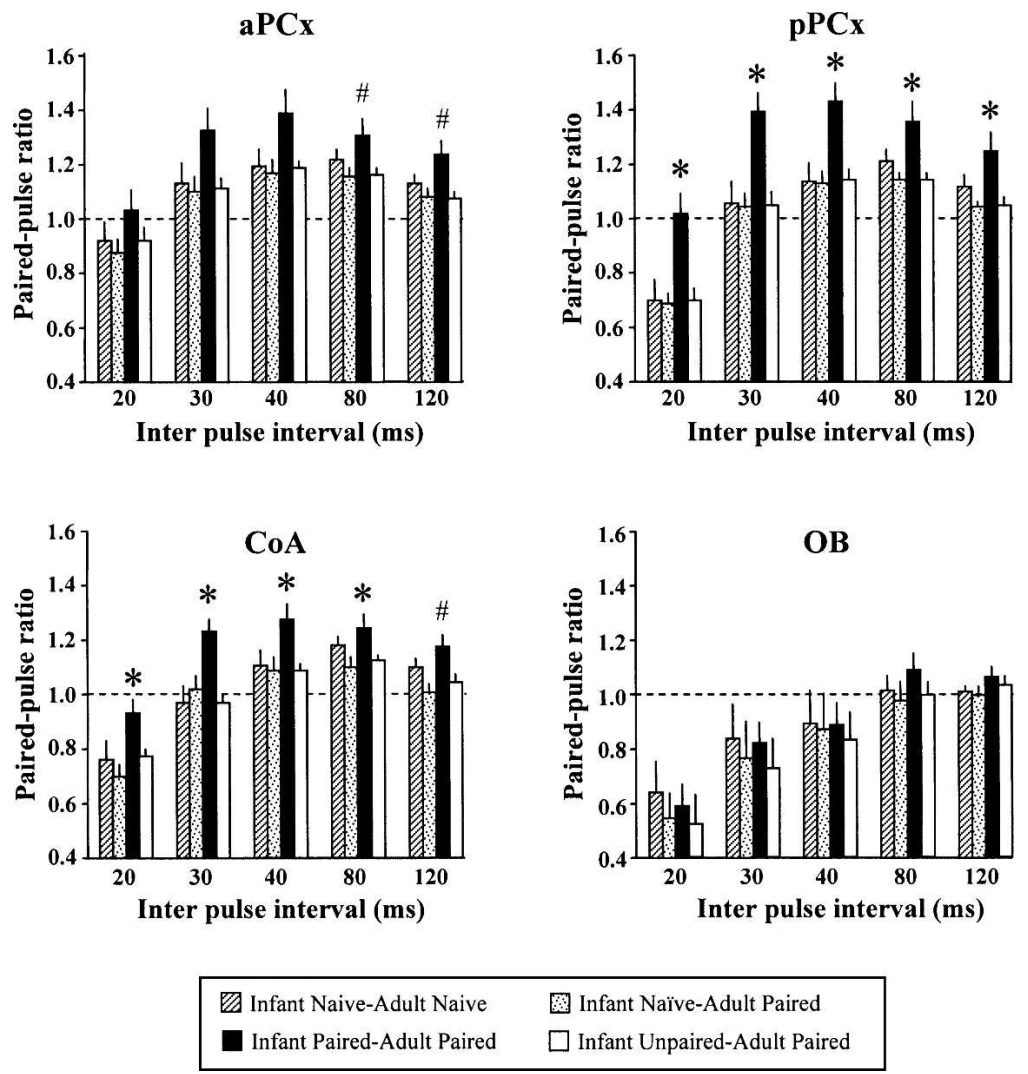

Figure 3. Mean paired-pulse ratios (mean test signal amplitude/mean conditioning signal amplitude \pm SEM) obtained in the different experimental groups, in four structures: anterior (aPCX) and posterior ( $\mathrm{pPCx}$ ) piriform cortex, cortical nucleus of the amygdala (CoA), and olfactory bulb (OB). Paired-pulse stimulations were delivered using different interpulse interval durations (20-120 msec). A ratio $<1$ characterizes paired-pulse inhibition, whereas a ratio $>1$ corresponds to paired-pulse facilitation. $\left({ }^{*}\right)$ Significant difference with all the other groups $(P<0.05)$. (\#) Significant differences with all but Infant Naive/Adult Naive groups $(P<0.05)$. 
2-DG activation in pPCx and CoA compared to control animals. Moreover, electrophysiological assessment carried out in the absence of the learned odor, revealed that in these sites paired-pulse inhibition was lower than in control animals. In contrast 2-DG uptake in aPCx was not affected and paired-pulse inhibition was only slightly modified. The most salient implications of early life experience effects on adult cognition are the following: (1) The effects are widespread and include sensory cortical areas in addition to amygdala and (2) areas important for learning in adulthood are modified by early life experience, despite their lack of plasticity in early life learning.

\section{Attenuated adult fear conditioning after early life experience}

Our behavioral results confirm the data reported in our previous study indicating that early life experience with paired (but not unpaired) odor-shock conditioning attenuates adult fear learning (Sevelinges et al. 2007). While early life experiences (handling, maternal deprivation, level of maternal care) have previously been shown to alter later life context and cue fear learning (Kosten et al. 2005, 2006; Diorio and Meaney 2007), our results suggest the contingency of early life experience plays an important role in determining outcome (present results, Sevelinges et al. 2007). These attenuating effects of infant stress on adult fear learning are in sharp contrast to stress effects in adulthood, which facilitate learning (Cordero et al. 2003; Roozendaal et al. 2006).

\section{Early learning alters the functioning of olfactory structures involved in adult odor fear learning}

Infant Naive/Adult Paired and Infant Unpaired/Adult Paired animals, which showed normal odor fear conditioning, exhibited increased 2-DG uptake in the CoA and pPCx but not the aPCx, compared to Infant Odor/Adult Odor animals. These results complement previous data showing that odor fear conditioning was associated with synaptic plasticity within these two structures, as assessed during the CS odor retention test (Sevelinges et al. 2004), and further document the differential role of anterior and posterior parts of the piriform cortex in olfactory learning. Indeed there is now increasing evidence that, whereas the aPCx is involved in sensory processes and simple forms of short-term memory like habituation (Wilson 1998a,b, 2000; Kadohisa and Wilson 2006) or perceptual learning (Wilson 2003), the pPCx is involved in more cognitive mnesic processes including the learning and recall of associations between odorants and information from other sensory modalities (Litaudon et al. 1997, 2003; Chabaud et al. 1999, 2000; Haberly 2001; Mouly et al. 2001; Mouly and Gervais 2002; Sevelinges et al. 2004; Jones et al. 2007).

In contrast to Infant Naive/Adult Paired animals, acquisition-induced 2-DG uptake was attenuated in pPCx and CoA of Infant Paired/Adult Paired animals and appeared similar to nonlearning groups such as the Infant Odor/Adult Odor animals. It should be noted that the lack of a significant difference in 2-DG uptake between Infant Paired/Adult Paired animals and nonlearning groups does not indicate similar processing since 2-DG requires prolonged and robust differences in neural activity, thus precluding the detection of subtle differences.

To better characterize mechanisms responsible for attenuated fear learning in Infant Paired/Adult Paired animals, we performed EFP recordings in response to paired-pulse stimulation of the $\mathrm{OB}$ to assess the time course of short-term inhibition and facilitation processes in the different sites. In Infant Naive/Adult Naive animals, paired-pulse stimulation of the OB induced inhibition or facilitation depending on the duration of the interpulse interval. In accordance with data reported in a previous study
(Mouly and Di Scala 2006), inhibition was observed in the three recording sites for short interpulse intervals $(20 \mathrm{msec})$, with a lower degree of inhibition in aPCx than in the PPCx and CoA. At longer interpulse intervals (40-120 msec), paired-pulse facilitation was observed in the three structures which confirm previous data (Haberly 1973; Schwob et al. 1984; Patneau and Stripling 1992; Best and Wilson 2004; McNamara et al. 2004). This approach first revealed that normal adult odor fear learning did not alter paired-pulse inhibition or facilitation in the three recorded areas since paired-pulse ratios were similar in Infant Naive/Adult Paired and Infant Naive/Adult Naive animals. In contrast, Infant Paired/Adult Paired animals presented alterations in the level of inhibition in the pPCx and CoA and to a lesser extent in the aPCx. Specifically, paired-pulse inhibition normally observed for short interpulse intervals was strongly attenuated in $\mathrm{PPCx}$ and CoA, and switched to paired-pulse facilitation for longer stimulation intervals in Infant Paired/Adult Paired animals. Therefore, the $\mathrm{pPCx}$ and $\mathrm{CoA}$ which are not involved in infant odor-shock learning presented alterations in adult animals, whereas aPCx, a structure involved in infant odor-shock learning, only showed minor modifications.

Paired-pulse inhibition mainly reflects the inhibitory feedback exerted by local GABAergic interneurons onto the main glutamatergic projection neurons (for the piriform cortex: Tseng and Haberly [1988] and Princivalle et al. [2000]; for the amygdala: Sah et al. [2003] and Muller et al. [2006]). Paired-pulse facilitation is usually considered to reflect an increase in transmitter release due to residual $\mathrm{Ca}^{2+}$ accumulation in the presynaptic terminal (for reviews, see Fortune and Rose 2001; Zucker and Regehr 2002). In Infant Paired/Adult Paired animals both phenomena seem to have been altered. Indeed paired-pulse inhibition was strongly attenuated in $\mathrm{pPCx}$ and $\mathrm{CoA}$, and paired-pulse facilitation was increased for longer stimulation intervals. At first sight, these data could seem contradictory with the decrease in 2-DG uptake observed in the same sites in this experimental group. Indeed, attenuation in inhibition would logically predict an increase in 2-DG uptake. However, one must keep in mind that variations in 2-DG uptake can be interpreted as changes in either excitatory or inhibitory neuron activity. Interestingly, pairing of an odor with stroking in rat pups was shown to induce an odor preference which correlated with an increase in 2-DG uptake in the OB (Sullivan and Leon 1986) and a parallel increase in inhibition of mitral/tufted cells response to the learned odor (Wilson et al. 1987). In the present study, the decrease in 2-DG uptake observed in pPCx and CoA could therefore reflect a decrease in inhibitory neuron activity, although further experiments are needed to properly address this question. In addition, this explanation only stands for short IPIs and cannot explain the increase in paired-pulse facilitation at longer intervals.

\section{Are the changes observed in cortical areas a consequence of changes in the $O B$ ?}

In our previous study (Sevelinges et al. 2007) we reported that early experience resulted in an increased 2-DG uptake in the OB during adult odor fear learning. These data suggest the $O B$ is sending altered odor input to the olfactory cortical areas and may contribute to their altered response to adult conditioning. Although further experiments are needed to address this question, two arguments seem to discard this hypothesis. First, in PairedPaired animals, 2-DG assessment showed that the activity of aPCx, which is the main target of the OB output neurons, is not modified by early experience, despite a strong increase in $\mathrm{OB}$ 2-DG uptake. Secondly, in the present study, paired-pulse inhibition measured in the OB was not modified in Infant Paired/ Adult Paired animals whereas it was altered in $\mathrm{pPCx}$ and CoA. 
These results suggest a dissociation between modifications observed in the $\mathrm{OB}$ and olfactory structures on which it projects.

\section{Are the changes observed in cortical areas responsible for changes in amygdala?}

In our previous study (Sevelinges et al. 2007) we reported that early experience resulted in a decrease in 2-DG uptake in the basolateral amygdala during adult odor fear learning. In the present study, as indicated by 2-DG autoradiography and electrophysiology, the CoA appears altered by early life paired odorshock conditioning. The CoA is an amygdala nucleus considered part of the olfactory cortex and receives input directly from the OB but also from the aPCx and pPCx (Kajiwara et al. 2007), although the link between the $\mathrm{pPCx}$ and $\mathrm{CoA}$ is much greater (Price 1973; McDonald 1998; Swanson and Petrovich 1998). In contrast the basolateral amygdala does not receive projections from the $\mathrm{OB}$ and receives relatively weak projections from the piriform cortex (Krettek and Price 1978; Ottersen 1982; Luskin and Price 1983). However, it receives fairly dense projections from the corticomedial amygdala including the CoA (Savander et al. 1996; Sah et al. 2003). The reliance of the basolateral amygdala on CoA input may indicate altered input rather than local changes and could, at least in part, underlie the altered functioning of this important site for fear learning plasticity.

\section{Functional interpretation}

Taken together these data suggest that early life paired odorshock conditioning has enduring effects on a wide network of structures, from the first relay of olfactory information $(\mathrm{OB}$, Sevelinges et al. [2007]) to the olfactory cortical areas (pPCx, CoA, present study) and the basolateral amygdala (Sevelinges et al. 2007). Thus, each structure along the olfactory pathway likely alters the signal as it travels to the amygdala, which may result in the observed attenuated learning. Interestingly, the sites which presented an altered functioning in adult animals were different, at least in part, from those involved in odor memory formation in infant learning (see Table 1; Sullivan and Wilson 1995; Roth and Sullivan 2005; Moriceau et al. 2006). The present work complements earlier data on compromised adult learning and emotionality derived from other early life experience paradigms, such as painful shock or separation from the mother (Levine 1957, 1962; Denenberg and Bell 1960; Bell and Denenberg 1962; Lindholm 1962; Denenberg 1963; Henderson 1965; Coplan et al. 1996; Caldji et al. 1998, 2000; Pryce and Feldon 2003; Seckl and Meaney 2004; Card et al. 2005; Kosten et al. 2005, 2006). Here, we present data suggesting that mechanisms associated with the enduring effects of early life experience are greatly dependent upon the contingent presentation of odor and shock (i.e., not found in unpaired infant experience groups), and the resulting effects are not limited to brain areas, showing learning-induced plasticity in infancy (see Table 1).

Table 1. Infant and adult odor-shock conditioning involves distinct patterns of plasticity in the brain

\begin{tabular}{lccccc}
\hline & $\begin{array}{c}\text { Olfactory } \\
\text { bulb }\end{array}$ & $\begin{array}{c}\text { Anterior } \\
\text { piriform } \\
\text { cortex }\end{array}$ & $\begin{array}{c}\text { Posterior } \\
\text { piriform } \\
\text { cortex }\end{array}$ & $\begin{array}{c}\text { Cortical } \\
\text { amygdala }\end{array}$ & $\begin{array}{c}\text { Basolateral } \\
\text { amygdala }\end{array}$ \\
\hline Infant & $\sqrt{ }$ & $\sqrt{ }$ & & & \\
Adult & & & $\sqrt{ }$ & $\sqrt{ }$ & $\sqrt{ }$ \\
Infant/Adult & $\sqrt{ }$ & & $\sqrt{ }$ & $\sqrt{ }$ & $\sqrt{ }$ \\
\hline
\end{tabular}

Note that infant paired odor-shock experience (Infant/Adult) alters the pattern of plasticity of the adult pathway.

\section{Materials and Methods}

\section{Subjects and husbandry}

A total of 67 animals were used in this experiment. Male Long Evans rats were born in the respective institutions animal care facilities from dams housed in polypropylene cages $(34 \times 29 \times 17$ $\mathrm{cm}$ ) lined with abundant pine shavings, ad libitum food and water and kept in a temperature $\left(23^{\circ} \mathrm{C}\right)$ and light $(7-19 \mathrm{~h})$ controlled room. Mothers were either purchased pregnant (France) or bred (USA) in the facilities. The day of parturition was considered PNO and culling of litters to 12 pups occurred on PNO-1. To prevent litter effects on statistical analysis, no more than one male from a litter was used in an experimental training/testing condition. Pups were weaned at PN21-23 and adult fear conditioning occurred when rats were 4-6 mo old. Institutional approval was received for all procedures, which followed the NIH (USA) and European guidelines (France). An overlap in personnel training/ testing of both infant and adult rats in both France and the USA ensured consistency of conditioning and testing of infant and adult animals between laboratories.

\section{Infant odor-shock conditioning}

PN8 pups were assigned to one of the following experimental groups: (1) Paired odor-shock, (2) Unpaired odor-shock, (3) Odor Only, and (4) Naive. Pups were trained daily for five consecutive days in order to induce a strong learning. In paired condition, this paradigm causes pups to learn an odor preference provided conditioning is begun during the sensitive period (Sevelinges et al. 2007). The Paired group received 11 presentations of a 30-sec conditioned stimulus (CS; McCormick Pure Peppermint; 2 L/min 1:10 peppermint vapor to air) and a 1-sec unconditioned stimulus (US; hind limb shock; $0.5 \mathrm{~mA}$ ). Peppermint odor was delivered via an olfactometer controlled by a Chrontrol with an intertrial interval of $4 \mathrm{~min}$. The Unpaired group was shocked 1.5-2 min following the CS odor presentation and the Odor-Only group received only the odor CS. Naive pups did not receive odor or shock and were always from a litter without any conditioned pups. Pups were placed in individual $600-\mathrm{mL}$ clear plastic cylinders, immediately after being removed from the nest, given 10 min to recover from experimenter handling, and were returned immediately to the nest following the 45-min training.

\section{Infant odorant CS test}

To ensure that odor-shock conditioning from PN8 to PN12 leads to an odor preference in our conditions 15 extra pups were trained in one of these three conditions: (1) Paired, (2) Unpaired, or (3) Odor Only. The day after conditioning, pups were given a Y-maze test. This test required pups to choose between two arms of a Plexiglas Y maze (start box: $8.5 \times 10 \times 8 \mathrm{~cm}$; choice arms: $8.5 \times 24 \times 8 \mathrm{~cm})$ : one containing the peppermint odor CS $(20 \mu \mathrm{L}$ of peppermint odor placed on a Kim Wipe), and the other containing the familiar odor of pine shavings $(20 \mathrm{~mL}$ of clean shaving in a Petri dish). A pup was placed in the start box (habituation chamber) during the $5 \mathrm{sec}$ before the door to each alley was opened. Each pup was given $60 \mathrm{sec}$ to choose an arm. A response was considered a choice when a pup's entire body was past the entrance to the alley. Pups received five trials with $30 \mathrm{sec}$ between trials, and the floor was wiped clean between each trial (Sullivan and Wilson 1991). Testing was done blind to the training condition. These pups were not trained at adulthood in order to avoid possible interferences of this unreinforced CS exposure on the strength of the previous CS-US learning.

\section{Adult odor-shock conditioning}

Conditioning took place in a Plexiglas transparent cylinder (diameter $=21 \mathrm{~cm}$, height $=21.5 \mathrm{~cm})$ with a lateral door $($ Vigouroux and Royet 1981), housed in a sound attenuating enclosure. The floor of the cage consisted of 17 stainless steel bars, $0.5 \mathrm{~cm}$ in diameter, spaced $1 \mathrm{~cm}$ apart. The floor was connected to a Coulbourn shock generator, which delivered 0.4-mA scrambled shock. The ceiling of the cage allowed the branching of three 
Table 2. Summary of the different experimental groups with respect to Infant and Adult condition, as well as neurobiological assessment in adulthood

\begin{tabular}{lll}
\hline Infant & Adult & Neurobiological assessment \\
\hline Naive & Naive & Electrophysiology \\
Naive & Paired & 2-DG/Electrophysiology \\
Paired & Paired & 2-DG/Electrophysiology \\
Unpaired & Paired & 2-DG/Electrophysiology \\
Odor & Odor & 2-DG \\
\hline
\end{tabular}

Tygon tubing connected to an olfactometer located outside the apparatus. Deodorized air constantly flowed through the cage. At appropriate times, the odor was introduced in the air stream for 30 sec. The conditioning cage was placed above a cubic Plexiglas chamber $(30 \times 30 \times 15 \mathrm{~cm})$ on which an exhaust fan was mounted allowing a continuous evacuation of the odorant stream from the conditioning cage. Conditioning took place in a single session. Rats were introduced in the conditioning cage and given 2 min of free exploration. At the third minute, peppermint was introduced in the cage for $30 \mathrm{sec}$, the last $2 \mathrm{sec}$ of which overlapped with the delivery of $0.4-\mathrm{mA}$ foot-shock (US). The animals received six pairings of odor and shock with an intertrial interval of $4 \mathrm{~min}$. Five different experimental groups were used based on the infant and adult training conditions: Infant Naive/Adult Naive, Infant Paired/Adult Paired, Infant Unpaired/Adult Paired, Infant Naive/Adult Paired, Infant Odor/Adult Odor (Table 2). Animals were divided in two distinct experiments. A first set of rats $(n=20)$ served for 2-DG autoradiography experiment. The second set $(n=47)$ served for cue testing and electrophysiological studies.

\section{Autoradiography analysis of the olfactory cortical areas}

The first set of adult rats (Infant Paired/Adult Paired, $n=5$; Infant Unpaired/Adult Paired, $n=4$; Infant Naive/Adult Paired, $n=6$; Infant Odor/Adult Odor, $n=5$ ) was injected with ${ }^{14} \mathrm{C} 2$-deoxyglucose (2-DG; $40 \mu \mathrm{Ci} \mathrm{sc/rat)} 5 \mathrm{~min}$ before adult odor-shock conditioning. Brains were removed immediately after conditioning, frozen in 2 -methylbutane $\left(-45^{\circ} \mathrm{C}\right)$ and stored at $-70^{\circ} \mathrm{C}$. At $-20^{\circ} \mathrm{C}$ brains were sectioned $(20 \mu \mathrm{m})$ in a cryostat with alternating sections mounted and exposed for $5 \mathrm{~d}$ with standards $\left({ }^{14} \mathrm{C}\right.$ methylmethacrylate standard $10 \times 0.02 \mathrm{mCi}$; American Radiolabeled Chemicals, Inc.) (DiRocco and Hall 1981; Coopersmith and Leon 1986; Nudo and Masterton 1986; Sullivan and Wilson 1995). Analysis was done by an experimenter blind to the experiment conditions using the NIH computer-based digital image system that allows pseudocolor imaging and quantitative optical densitometry of autoradiographs.

Olfactory cortical areas examined were the aPCx and pPCx, as well as the CoA. Brain areas were identified by counterstaining sections with cresyl violet and a template constructed to overlay on the autoradiographs to determine the areas for analysis (Paxinos and Watson 1986). The 2-DG uptake was expressed relative to 2-DG uptake in the corpus callosum (which did not vary between conditioning group) to control for differences in section thickness and exposure (Sullivan et al. 2000; Moriceau and Sullivan 2004; Moriceau et al. 2006).

\section{Cue testing in adulthood}

Assessment of CS-conditioned fear in the second set of adult rats was performed $24 \mathrm{~h}$ after the conditioning session, in a testing cage different from the conditioning cage in order to avoid the influence of fear conditioning to the training context (Holland and Bouton 1999). Rats were introduced in the testing cage and conditioned fear to the odor was assessed in an 8-min session. During the first two minutes of testing, no odorant was present and the rats were free to explore their environment. The CS odor was then presented during the first $30 \mathrm{sec}$ of each of the following 6 min. Animals' behavior was continuously monitored with a camera connected to a video-recorder for off-line analysis. Offline, animals' behavior recorded during the test sessions was rated using an ethological keyboard connected to customized
Matlab software. Freezing, which was characterized by a crouching posture and an absence of any visible movement except that due to breathing (Blanchard and Blanchard 1969), was quantified as total percent time during baseline prior to the odor presentations (pre-odor period) and during the odor presentations (odor period).

\section{Electrophysiological assessment of the olfactory cortical areas}

Two days after the cue-testing session, animals from different experimental groups (Infant Naive/Adult Naive, $n=11$; Infant Paired/Adult Paired, $n=13$; Infant Unpaired/Adult Paired, $n=12$; Infant Naive/Adult Paired, $n=11$ ) were anesthetized with Equithesin (mixture of chloral hydrate and sodium pentobarbital; $3 \mathrm{~mL} / \mathrm{kg}$, i.p.). The level of anesthesia was held constant with regular injections of Equithesin throughout the experiment. A bipolar stimulating electrode was lowered in the left $\mathrm{OB}(\mathrm{A} / \mathrm{P}-6$ $\mathrm{mm}$ relative to the nasofrontal suture, $\mathrm{L} / \mathrm{M} 1.3 \mathrm{~mm}$ relative to Bregma) at the level of the mitral cell layer. Three monopolar recording electrodes were implanted ipsilaterally in the $\mathrm{aPCx}$ $(\mathrm{A} / \mathrm{P}+2.2 \mathrm{~mm}, \mathrm{~L} / \mathrm{M} 4 \mathrm{~mm}$ relative to Bregma), the $\mathrm{pPCx}(\mathrm{A} / \mathrm{P}-1.8$ $\mathrm{mm}, \mathrm{L} / \mathrm{M} 5.5 \mathrm{~mm}$ to Bregma), and the CoA (A/P $-2.3 \mathrm{~mm}, \mathrm{~L} / \mathrm{M}$ $3.3 \mathrm{~mm}$ relative to Bregma) (Fig. 4A). Accurate positioning of recording electrodes depth was achieved using the field potential profile evoked in each structure in response to electrical stimulation of the bipolar OB electrodes (Fig. 4B; Mouly and Di Scala 2006). In aPCx, pPCx, and CoA, recording electrode tips were positioned in the deep cortical layers (layers II-III) where the field potential signal presented large stable amplitude, which corresponded to the approximate depths of $-7 \mathrm{~mm},-8 \mathrm{~mm}$, and -9 $\mathrm{mm}$, respectively. In a subgroup of animals $(n=26)$, a second bipolar stimulating electrode was lowered in the left LOT in order to induce antidromic EFP in the OB collected via the stimulation electrode implanted at this level.

Electrical stimulation was delivered in the $\mathrm{OB}$ or LOT through a Master-8 stimulator (AMPI). The electrical stimulus was a single monophasic square pulse, $0.1-\mathrm{msec}$ duration, $0.1-\mathrm{Hz}$

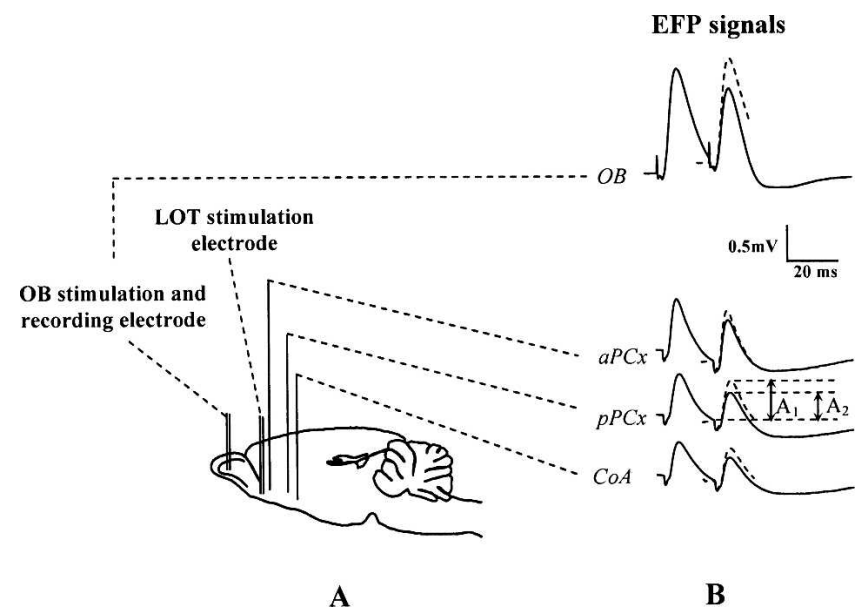

Figure 4. Schematic representation of the implanted electrodes and recorded evoked field potential (EFPs) signals. (A) A bipolar stimulation electrode was inserted in the mitral cell layer of the olfactory bulb (OB) and in the lateral olfactory tract (LOT) for a subgroup of animals. Three monopolar recording electrodes were, respectively, implanted in the anterior piriform cortex (aPCx), posterior piriform cortex (pPCx), and cortical nucleus of the amygdala (COA). Moreover, the bipolar electrode implanted in the $\mathrm{OB}$ also served as a recording electrode during stimulation of the LOT. (B) An example of EFPs induced in the four recording sites in response to paired-pulse stimulation of the OB (aPCx, pPCx, CoA) or the LOT (OB) using a 20-msec interpulse interval. Paired-pulse ratio was defined as the ratio of mean test signal amplitude $\left(A_{2}\right.$, second pulse) over mean conditioning signal $\left(A_{1}\right.$, first pulse). A decrease in the size of the response to the second pulse suggests inhibition and is reflected in a ratio $<1$. 
frequency. Stimulation test intensity $(300-500 \mu \mathrm{A})$ was set to induce a response amplitude of $\sim 70 \%$ of maximum in the different recording sites. EFPs were amplified (Grass Model 12, AstroMed, Inc.), filtered (1-300 Hz), and digitized (sampling frequency: $5 \mathrm{kHz}$ ) using a data acquisition system (Wavebook 512, Lotech, Inc.) for storage on computer hard disk.

Paired-pulse stimulation of the OB or LOT was used to assess the time course of short-term inhibition and facilitation in the different recording sites. In these tests, the effect of the conditioning (first) pulse was assessed by measuring changes in the response to the test (second) pulse. A ratio Test/Conditioning $<1$ is observed when the response to the test pulse is smaller than the response to the conditioning pulse and characterizes paired-pulse inhibition. Inversely, a ratio $>1$ is obtained when the response to the test pulse is greater than the response to the first pulse and corresponds to paired-pulse facilitation. Paired pulses were delivered at interpulse intervals of 20,30, 40, 80, and 120 msec. Twelve responses were recorded for averaging at each interpulse interval.

Off-line, individual EFPs were averaged ( $n=12$ sweeps) and analyzed using the data acquisition software Dasylab (Iotech, Inc.). In each recording site, peak amplitudes of both the conditioning and test pulses were measured. Test signal amplitude was expressed as a ratio of conditioning signal amplitude. The obtained ratios were compared between the different experimental groups.

\section{Statistical analysis}

For all the experiments, comparisons were made using an analysis of variance (ANOVA), followed by paired Student's $t$-test for within group comparisons and post-hoc Fisher tests for between group comparisons. For all the statistical comparisons performed, the significance level was set at 0.05 .

\section{Acknowledgments}

This work was supported by NICHD HD33402, NSF IOB0544406, OCAST, OU Presidential International Travel Funds to R.M.S.; a Eurodoc grant to Y.S.; and financial support of the Agence Nationale de la Recherche (ANR), The French National Research Agency under the Programme National de Recherche en Alimentation et nutrition humaine project ANR-05-PNRA-1.E7 AROMALIM to A.M.M. We thank Charlis Raineki, Stephanie Moriceau, Parker Holman, and Kyle Muzny for assistance with this project.

\section{References}

Anisman, H., Zaharia, M.D., Meaney, M.J., and Merali, Z. 1998. Do early-life events permanently alter behavioral and hormonal responses to stressors? Int. I. Dev. Neurosci. 16: 149-164.

Barr, G.A. 1995. Ontogeny of nociception and antinociception. NIDA Res. Monogr. 158: 172-201.

Bell, R.W. and Denenberg, V.H. 1962. The interrelationships of shock and critical periods in infancy as they affect adult learning and activity. Anim. Behav. 11: 21-27.

Best, A.R. and Wilson, D.A. 2004. Coordinate synaptic mechanisms contributing to olfactory cortical adaptation. J. Neurosci. 24: $652-660$.

Blanchard, R.J. and Blanchard, D.C. 1969. Crouching as an index of fear. J. Comp. Physiol. Psychol. 67: 370-375.

Caldji, C., Tannenbaum, B., Sharma, S., Francis, D., Plotsky, P.M., and Meaney, M.J. 1998. Maternal care during infancy regulates the development of neural systems mediating the expression of fearfulness in the rat. Proc. Natl. Acad. Sci. 95: 5335-5340.

Caldji, C., Diorio, J., and Meaney, M.J. 2000. Variations in maternal care in infancy regulate the development of stress reactivity. Biol. Psychiatry 48: 1164-1174.

Camp, L.L. and Rudy, J.W. 1988. Changes in the categorization of appetitive and aversive events during postnatal development of the rat. Dev. Psychobiol. 21: 25-42.

Card, J.P., Levitt, P., Gluhovsky, M., and Rinaman, L. 2005. Early experience modifies the postnatal assembly of autonomic emotional motor circuits in rats. J. Neurosci. 25: 9102-9111.

Chabaud, P., Ravel, N., Wilson, D.A., and Gervais, R. 1999. Functional coupling in rat central olfactory pathways: A coherence analysis.
Neurosci. Lett. 276: 17-20.

Chabaud, P., Ravel, N., Wilson, D.A., Mouly, A.M., Vigouroux, M., Farget, V., and Gervais, R. 2000. Exposure to behaviourally relevant odour reveals differential characteristics in rat central olfactory pathways as studied through oscillatory activities. Chem. Senses 25: $561-573$.

Collier, A.C. and Bolles, R.C. 1980. The ontogenesis of defensive reactions to shock in preweanling rats. Dev. Psychobiol. 13: 141-150.

Coopersmith, R. and Leon, M. 1986. Enhanced neural response by adult rats to odors experienced early in life. Brain Res. 371: 400-403.

Coplan, J.D., Andrews, M.W., Rosenblum, L.A., Owens, M.J., Friedman, S., Gorman, J.M., and Nemeroff, C.B. 1996. Persistent elevations of cerebrospinal fluid concentrations of corticotropin-releasing factor in adult nonhuman primates exposed to early-life stressors: Implications for the pathophysiology of mood and anxiety disorders. Proc. Natl. Acad. Sci. 93: 1619-1623.

Cordero, M.I., Venero, C., Kruyt, N.D., and Sandi, C. 2003. Prior exposure to a single stress session facilitates subsequent contextual fear conditioning in rats. Evidence for a role of corticosterone. Horm. Behav. 44: $338-345$.

Cousens, G. and Otto, T. 1998. Both pre- and posttraining excitotoxic lesions of the basolateral amygdala abolish the expression of olfactory and contextual fear conditioning. Behav. Neurosci. 112: 1092-1103.

Davis, M. 1997. Neurobiology of fear responses: The role of the amygdala. J. Neuropsychiatry Clin. Neurosci. 9: 382-402.

Denenberg, V.H. 1963. Early experience and emotional development. Sci. Am. 208: 138-146.

Denenberg, V.H. and Bell, R.W. 1960. Critical periods for the effects of infantile experience on adult learning. Science 131: 227-228.

Diorio, J. and Meaney, M.J. 2007. Maternal programming of defensive responses through sustained effects on gene expression. J. Psychiatry Neurosci. 32: 275-284.

DiRocco, R.J. and Hall, W.G. 1981. Metabolic neural mapping in neonatal rats. J. Neurosci. Res. 6: 13-19.

Fanselow, M.S. and Gale, G.D. 2003. The amygdala, fear, and memory. Ann. N. Y. Acad. Sci. 985: 125-134.

Fitzgerald, M. 2005. The development of nociceptive circuits. Nat. Rev. Neurosci. 6: 507-520.

Fleming, A.S., O'Day, D.H., and Kraemer, G.W. 1999. Neurobiology of mother-infant interactions: Experience and central nervous system plasticity across development and generations. Neurosci. Biobehav. Rev. 23: 673-685.

Fortune, E.S. and Rose, G.J. 2001. Short-term synaptic plasticity as a temporal filter. Trends Neurosci. 24: 381-385.

Funk, D. and Amir, S. 2000. Enhanced Fos expression within the primary olfactory and limbic pathways induced by an aversive conditioned odor stimulus. Neuroscience 98: 403-406.

Haberly, L.B. 1973. Summed potentials evoked in opossum prepyriform cortex. J. Neurophysiol. 36: 775-788.

Haberly, L.B. 2001. Parallel-distributed processing in olfactory cortex: New insights from morphological and physiological analysis of neuronal circuitry. Chem. Senses 26: 551-576.

Haroutunian, V. and Campbell, B.A. 1979. Emergence of interoceptive and exteroceptive control of behavior in rats. Science 205: 927-929.

Henderson, N.D. 1965. Acquisition and retention of conditioned fear during different stages in the development of mice. J. Comp. Physiol. Psychol. 59: 439-442.

Holland, P.C. and Bouton, M.E. 1999. Hippocampus and context in classical conditioning. Curr. Opin. Neurobiol. 9: 195-202.

Jones, S.V., Stanek-Rattiner, L., Davis, M., and Ressler, K.J. 2007. Differential regional expression of brain-derived neurotrophic factor following olfactory fear learning. Learn. Mem. 14: 816-820.

Kadohisa, M. and Wilson, D.A. 2006. Separate encoding of identity and similarity of complex familiar odors in piriform cortex. Proc. Natl. Acad. Sci. 103: 15206-15211.

Kajiwara, R., Tominaga, T., and Takashima, I. 2007. Olfactory information converges in the amygdaloid cortex via the piriform and entorhinal cortices: Observations in the guinea pig isolated whole-brain preparation. Eur. J. Neurosci. 25: 3648-3658.

Kilpatrick, L. and Cahill, L. 2003. Modulation of memory consolidation for olfactory learning by reversible inactivation of the basolateral amygdala. Behav. Neurosci. 117: 184-188.

Kosten, T.A., Miserendino, M.J., Bombace, J.C., Lee, H.J., and Kim, J.J. 2005. Sex-selective effects of neonatal isolation on fear conditioning and foot shock sensitivity. Behav. Brain Res. 157: 235-244.

Kosten, T.A., Lee, H.J., and Kim, J.J. 2006. Early life stress impairs fear conditioning in adult male and female rats. Brain Res. 1087: 142-150.

Krettek, J.E. and Price, J.L. 1978. A description of the amygdaloid complex in the rat and cat with observations on intra-amygdaloid axonal connections. J. Comp. Neurol. 178: 255-280. 
LeDoux, J.E. 2000. Emotion circuits in the brain. Annu. Rev. Neurosci. 23: $155-184$.

Levine, S. 1957. Infantile experience and resistance to physiological stress. Science 126: 405.

Levine, S. 1962. Plasma-free corticosteroid response to electric shock in rats stimulated in infancy. Science 135: 795-796.

Levine, S. 2001. Primary social relationships influence the development of the hypothalamic-pituitary-adrenal axis in the rat. Physiol. Behav. 73: $255-260$.

Levine, S. 2005. Developmental determinants of sensitivity and resistance to stress. Psychoneuroendocrinology 30: 939-946.

Lindholm, B.W. 1962. Critical periods and the effects of early shock on later emotional behavior in the white rat. J. Comp. Physiol. Psychol. 55: $597-599$.

Litaudon, P., Mouly, A.M., Sullivan, R., Gervais, R., and Cattarelli, M. 1997. Learning-induced changes in rat piriform cortex activity mapped using multisite recording with voltage sensitive dye. Eur. J. Neurosci. 9: 1593-1602.

Litaudon, P., Amat, C., Bertrand, B., Vigouroux, M., and Buonviso, N. 2003. Piriform cortex functional heterogeneity revealed by cellular responses to odours. Eur. I. Neurosci. 17: 2457-2461.

Luskin, M.B. and Price, J.L. 1983. The topographic organization of associational fibers of the olfactory system in the rat, including centrifugal fibers to the olfactory bulb. J. Comp. Neurol. 216: 264-291.

McDonald, A.J. 1998. Cortical pathways to the mammalian amygdala. Prog. Neurobiol. 55: 257-332.

McNamara, A.M., Cleland, T.A., and Linster, C. 2004. Characterization of the synaptic properties of olfactory bulb projections. Chem. Senses 29: $225-233$.

Moriceau, S. and Sullivan, R.M. 2004. Corticosterone influences on mammalian neonatal sensitive-period learning. Behav. Neurosci. 118: $274-281$

Moriceau, S., Wilson, D.A., Levine, S., and Sullivan, R.M. 2006. Dual circuitry for odor-shock conditioning during infancy: Corticosterone switches between fear and attraction via amygdala. J. Neurosci. 26: 6737-6748.

Mouly, A.M. and Di Scala, G. 2006. Entorhinal cortex stimulation modulates amygdala and piriform cortex responses to olfactory bulb inputs in the rat. Neuroscience 137: 1131-1141.

Mouly, A.M. and Gervais, R. 2002. Polysynaptic potentiation at different levels of rat olfactory pathways following learning. Learn. Mem. 9: 66-75.

Mouly, A.M., Fort, A., Ben-Boutayab, N., and Gervais, R. 2001. Olfactory learning induces differential long-lasting changes in rat central olfactory pathways. Neuroscience 102: 11-21.

Muller, J.F., Mascagni, F., and McDonald, A.J. 2006. Pyramidal cells of the rat basolateral amygdala: Synaptology and innervation by parvalbumin-immunoreactive interneurons. J. Comp. Neurol. 494: $635-650$.

Nudo, R.J. and Masterton, R.B. 1986. Stimulation-induced $\left[{ }^{14} \mathrm{C}\right] 2$-deoxyglucose labeling of synaptic activity in the central auditory system. J. Comp. Neurol. 245: 553-565.

Ottersen, O.P. 1982. Connections of the amygdala of the rat. IV: Corticoamygdaloid and intraamygdaloid connections as studied with axonal transport of horseradish peroxidase. J. Comp. Neurol. 205: $30-48$.

Patneau, D.K. and Stripling, J.S. 1992. Functional correlates of selective long-term potentiation in the olfactory cortex and olfactory bulb. Brain Res. 585: 219-228.

Paxinos, G. and Watson, C. 1986. The rat brain in stereotaxic coordinates. Academic Press, San Diego, CA.

Price, J.L. 1973. An autoradiographic study of complementary laminar patterns of termination of afferent fibers to the olfactory cortex. $J$. Comp. Neurol. 150: $87-108$.

Princivalle, A., Spreafico, R., Bowery, N., and De Curtis, M. 2000. Layer-specific immunocytochemical localization of $\mathrm{GABA}_{\mathrm{B}} \mathrm{R} 1 \mathrm{a}$ and $\mathrm{GABA}_{\mathrm{B}} \mathrm{R} 1 \mathrm{~b}$ receptors in the rat piriform cortex. Eur. J. Neurosci. 12: $1516-1520$.

Pryce, C.R. and Feldon, J. 2003. Long-term neurobehavioural impact of the postnatal environment in rats: Manipulations, effects and mediating mechanisms. Neurosci. Biobehav. Rev. 27: 57-71.

Roozendaal, B., Okuda, S., de Quervain, D.J., and McGaugh, J.L. 2006. Glucocorticoids interact with emotion-induced noradrenergic activation in influencing different memory functions. Neuroscience 138: $901-910$

Rosenkranz, J.A. and Grace, A.A. 2002. Dopamine-mediated modulation of odour-evoked amygdala potentials during pavlovian conditioning. Nature 417: 282-287.

Roth, T.L. and Sullivan, R.M. 2005. Memory of early maltreatment:
Neonatal behavioral and neural correlates of maternal maltreatment within the context of classical conditioning. Biol. Psychiatry 57: 823-831.

Sah, P., Faber, E.S., Lopez De Armentia, M., and Power, J. 2003. The amygdaloid complex: Anatomy and physiology. Physiol. Rev. 83: $803-834$.

Savander, V., LeDoux, J.E., and Pitkanen, A. 1996. Topographic projections from the periamygdaloid cortex to select subregions of the lateral nucleus of the amygdala in the rat. Neurosci. Lett. 211: $167-170$.

Schettino, L.F. and Otto, T. 2001. Patterns of Fos expression in the amygdala and ventral perirhinal cortex induced by training in an olfactory fear conditioning paradigm. Behav. Neurosci.

115: $1257-1272$.

Schwob, J.E., Haberly, L.B., and Price, J.L. 1984. The development of physiological responses of the piriform cortex in rats to stimulation of the lateral olfactory tract. I. Comp. Neurol. 223: 223-237.

Seckl, J.R. and Meaney, M.J. 2004. Glucocorticoid programming. Ann. N. Y. Acad. Sci. 1032: 63-84.

Sevelinges, Y., Gervais, R., Messaoudi, B., Granjon, L., and Mouly, A.M 2004. Olfactory fear conditioning induces field potential potentiation in rat olfactory cortex and amygdala. Learn. Mem. 11: 761-769.

Sevelinges, Y., Moriceau, S., Holman, P., Miner, C., Muzny, K., Gervais, R., Mouly, A.M., and Sullivan, R.M. 2007. Enduring effects of infant memories: Infant odor-shock conditioning attenuates amygdala activity and adult fear conditioning. Biol. Psychiatry 62: 1070-1079.

Stehouwer, D.J. and Campbell, B.A. 1978. Habituation of the forelimb-withdrawal response in neonatal rats. J. Exp. Psychol. Anim. Behav. Process. 4: 104-119.

Sullivan, R.M. and Leon, M. 1986. Early olfactory learning induces an enhanced olfactory bulb response in young rats. Brain Res. 392: $278-282$

Sullivan, R.M. and Wilson, D.A. 1991. Neural correlates of conditioned odor avoidance in infant rats. Behav. Neurosci. 105: 307-312.

Sullivan, R.M. and Wilson, D.A. 1995. Dissociation of behavioral and neural correlates of early associative learning. Dev. Psychobiol. 28: 213-219.

Sullivan, R.M., Landers, M., Yeaman, B., and Wilson, D.A. 2000. Good memories of bad events in infancy. Nature 407: 38-39.

Swanson, L.W. and Petrovich, G.D. 1998. What is the amygdala? Trends Neurosci. 21: 323-331.

Teicher, M.H., Tomoda, A., and Andersen, S.L. 2006. Neurobiological consequences of early stress and childhood maltreatment: Are results from human and animal studies comparable? Ann. N. Y. Acad. Sci. 1071: $313-323$.

Tseng, G.F. and Haberly, L.B. 1988. Characterization of synaptically mediated fast and slow inhibitory processes in piriform cortex in an in vitro slice preparation. J. Neurophysiol. 59: 1352-1376.

Vigouroux, M. and Royet, J.P. 1981. An olfactometric cage suitable for short duration stimulations of unrestrained small animals. $J$. Neurosci. Methods 4: 189-196.

Walker, D.L., Paschall, G.Y., and Davis, M. 2005. Glutamate receptor antagonist infusions into the basolateral and medial amygdala revea differential contributions to olfactory vs. context fear conditioning and expression. Learn. Mem. 12: 120-129.

Wilson, D.A. 1998a. Habituation of odor responses in the rat anterior piriform cortex. J. Neurophysiol. 79: 1425-1440.

Wilson, D.A. 1998b. Synaptic correlates of odor habituation in the rat anterior piriform cortex. J. Neurophysiol. 80: 998-1001.

Wilson, D.A. 2000. Odor specificity of habituation in the rat anterior piriform cortex. J. Neurophysiol. 83: 139-145.

Wilson, D.A. 2003. Rapid, experience-induced enhancement in odorant discrimination by anterior piriform cortex neurons. J. Neurophysiol. 90: $65-72$.

Wilson, D.A., Sullivan, R.M., and Leon, M. 1987. Single-unit analysis of postnatal olfactory learning: Modified olfactory bulb output response patterns to learned attractive odors. J. Neurosci. 7: $3154-3162$.

Zhang, T.Y., Bagot, R., Parent, C., Nesbitt, C., Bredy, T.W., Caldji, C., Fish, E., Anisman, H., Szyf, M., and Meaney, M.J. 2006. Maternal programming of defensive responses through sustained effects on gene expression. Biol. Psychol. 73: 72-89.

Zucker, R.S. and Regehr, W.G. 2002. Short-term synaptic plasticity. Annu. Rev. Physiol. 64: 355-405.

Received March 21, 2008; accepted in revised form July 1, 2008. 


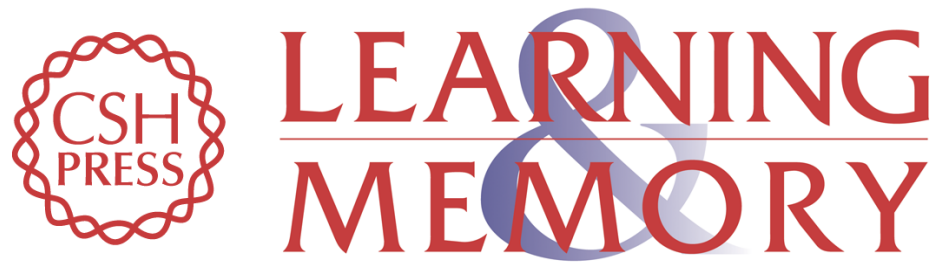

\section{Neonatal odor-shock conditioning alters the neural network involved in odor fear learning at adulthood}

Yannick Sevelinges, Regina M. Sullivan, Belkacem Messaoudi, et al.

Learn. Mem. 2008, 15:

Access the most recent version at doi:10.1101//m.998508

References This article cites 88 articles, 15 of which can be accessed free at:

http://learnmem.cshlp.org/content/15/9/649.full.html\#ref-list-1

License

Email Alerting Receive free email alerts when new articles cite this article - sign up in the box at the Service top right corner of the article or click here. 